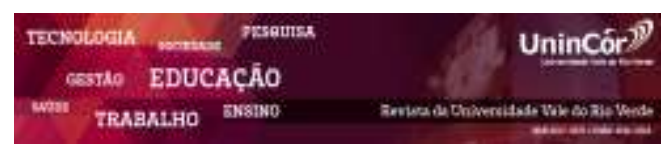

Revista da Universidade Vale do Rio Verde ISSN: 1517-0276 / EISSN: 2236-5362 Vol. 16 | n. 2 | Ano 2018

\begin{abstract}
Abraão Cícero da Silva
Universidade Federal Rural de Pernambuco abraaocicero@yahoo.com.br
\end{abstract}

Pedro Luís Ribeiro de Vasconcelos Universidade Federal Rural de Pernambuco pedroribeiro.ufrpe@gmail.com

Luan Danilo Ferreira de Andrade Melo Universidade Federal de Alagoas luan.danilo@yahoo.com.br

Vinicius Santos Gomes da Silva Universidade Federal de Alagoas vinicius.agro2008.1@gmail.com

João Luciano Melo de Andrade Júnior Universidade Federal de Alagoas luciiano.andrade@yahoo.com

Mayame de Brito Santana Universidade Federal Rural de Pernambucomayame.brito@hotmail.com

\section{DIAGNÓSTICO DA PRODUÇÃO DE FEIJÃO-CAUPI NO NORDESTE BRASILEIRO}

\begin{abstract}
RESUMO
O feijão-caupi é uma das alternativas de fonte de renda e alimento básico para população da região nordeste do Brasil. O caupi possui propriedades nutritivas ideais no combate à fome e à desnutrição. A maior produção do feijoeiro provém da agricultura familiar. O trabalho foi realizado nos municípios de Calçado, Jupí, Lajedo e São João no estado de Pernambuco Brasil. A pesquisa foi realizada no período de janeiro a maio de 2011. Neste trabalho foi realizado um levantamento dos principais entraveis enfrentados pelos produtores de feijão-caupí no nordeste brasileiro. Foram realizadas visitas as propriedades e entrevistados os agricultores sobre as principais dificuldades enfrentadas abordando toda a cadeia produtiva.
\end{abstract}

Palavras-chave:Agricultura sustentável. Agroecologia. Comercialização.Propriedades rurais. Vigna unguiculata L. Walp.

\section{DIAGNOSIS OF THE COWPEA PRODUCTION IN THE NORTHEAST BRAZIL}

\begin{abstract}
Cowpea is one of the alternatives of source of income and basic food for population of the northeast region of Brazil. It has ideal nutritional properties in the fight against hunger and malnutrition. The largest production of common bean comes from family farming. The work was carried out in the municipalities of Calçado, Jupí, Lajedo and São João in the state of Pernambuco, Brazil. The research was carried out from January to May 2011. In this work, I try to make a survey of the main obstacles faced by cowpea producers in the Brazilian northeast. Visits were made to the farms and farmers were interviewed about the main difficulties faced by the whole productive chain.
\end{abstract}

Keywords:Sustainable agriculture. Agroecology. Farms.Vigna unguiculata L. Walp.

Recebido em: 22/01/2018 - Aprovado em: 28/07/2018 - Disponibilizado em: 15/12/2018 


\section{INTRODUÇÃO}

O caupi (Vigna unguiculata (L.) Walp.) é uma leguminosa granífera de grande importância para alimentação humana sendo uma das principais fontes de proteína na dieta de populações pobres especialmente na América Latina e África (Oliveira et al., 2015). É uma cultura de origem africana, a qual foi introduzida no Brasil na segunda metade do século XVI pelos colonizadores portugueses no Estado da Bahia (FREIRE FILHO, 1988).

Na Região Nordeste do Brasil, a espécie assume grande importância socioeconômica, por ser um componente importante nos sistemas de produção e, também pelo alto valor nutritivo (ALMEIDA et al., 2010). Podendo ser consumido nas formas de grãos maduros e de grãos verdes. (FERREIRA \& SILVA, 1987).

É uma cultura cultivada em todos os estados da região nordeste brasileira. Apresentando destaque no setor produtivo o estado de Pernambuco sendo cultivado em quase todas as microrregiõesApesar da grande importância econômica e de ser cultivado em larga escala, tem sido verificado que os níveis de produtividade são inferiores ao potencial genético dessa culturaRosolem (1987).

Essa baixa produtividade pode estar relacionada com a falta de assistência técnica e a ausência de um programa de produção de sementes de alta qualidade. Pois a maior parte da produção do feijoeiro provém da agricultura familiar (80\%). E como esses produtores têm recursos limitados, muitas vezes, utilizam sementes de baixa qualidade e não desfrutam de assistência técnica, o que pode comprometer a qualidade da produção. Sendo que de acordo com Braccini \& Picanço (1995) as perdas nos sistemas de produção de grãos não só ocorrem em condições de campo, podendo se estender também no armazenamento quando esse não for feito de forma adequada.

Diante do exposto o presente trabalho teve como objetivo realizar um levantamento dos principais problemas enfrentados na cadeia de produção de feijão-caupi no nordeste brasileiro

\section{MATERIAL E MÉTODOS}

O levantamento foi realizado por meio de produtores rurais dosmunicípios de Calçado, Lajedo, São João, Jupí e Caetés, na mesorregião do Agreste de Pernambuco, que é um dos maiores polos produtores de feijão do estado de Pernambuco e do Nordeste brasileiro.

A pesquisa foi realizada no período de janeiro a maio de 2011. Foram realizadas visitas as propriedades rurais e entrevistados os proprietários. Durante a visita foi aplicado um questionário, no qual foi abordado um levantamento sobre o tamanho da área que é utilizada para o cultivo do feijão caupi e os principais problemas enfrentados no sistema de produção. Após a aplicação dos questionários, os dados foram analisados, tabulados e transformados em porcentagem e apresentados no formato de gráficos ilustrativos

Os dados analisados são de natureza primária, obtidos através de entrevistas diretas e coletados por meio de questionários estruturados aplicados aos agricultores familiares, pois nessas regiões predominam agricultura familiar. 


\section{RESULTADOS E DISCUSSÃO}

A Figura 1 mostra a distribuição de área territorial cultivada com feijão-caupi nos municípios de Calçado, Lajedo, São João e Caetés. Constatou-se que em todos municípios estudados o tamanho das propriedades rurais predominantes variaram entre 3 e 6 hectares de terra. E uma pequena minoria, menos de $10 \%$, têm propriedades rurais com uma área de 18 hectares. Dessa forma, a cultura do feijão-caupi concentra-se em pequenas propriedades rurais, o que desempenha um papel socioeconômico de grande importância para a população dessa região por ser um produto de qualidade nutricional excelente e por gerar muitos empregos na região. De acordo com Santos et al. (2008) um hectare de feijão-caupi gera 1,0 emprego/ano direto ao ano.

A

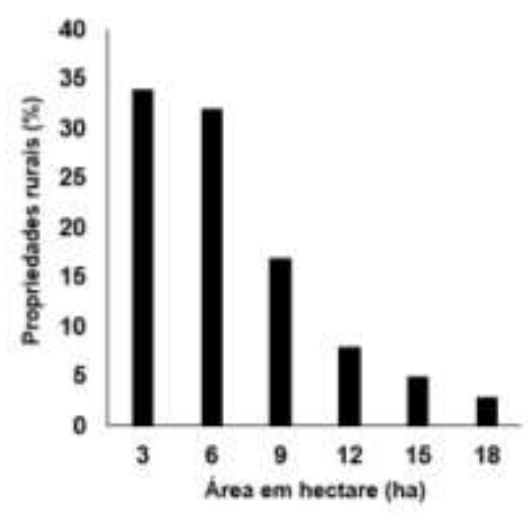

B

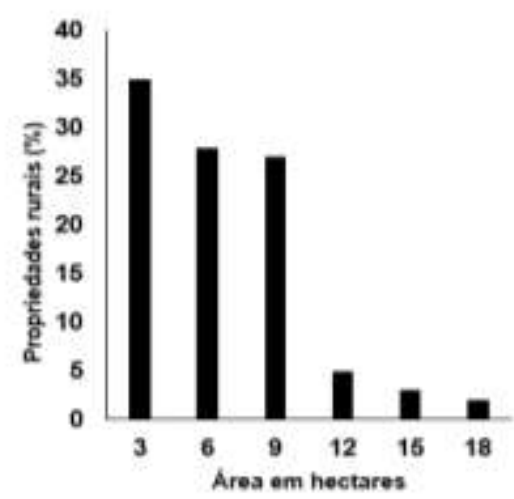

C
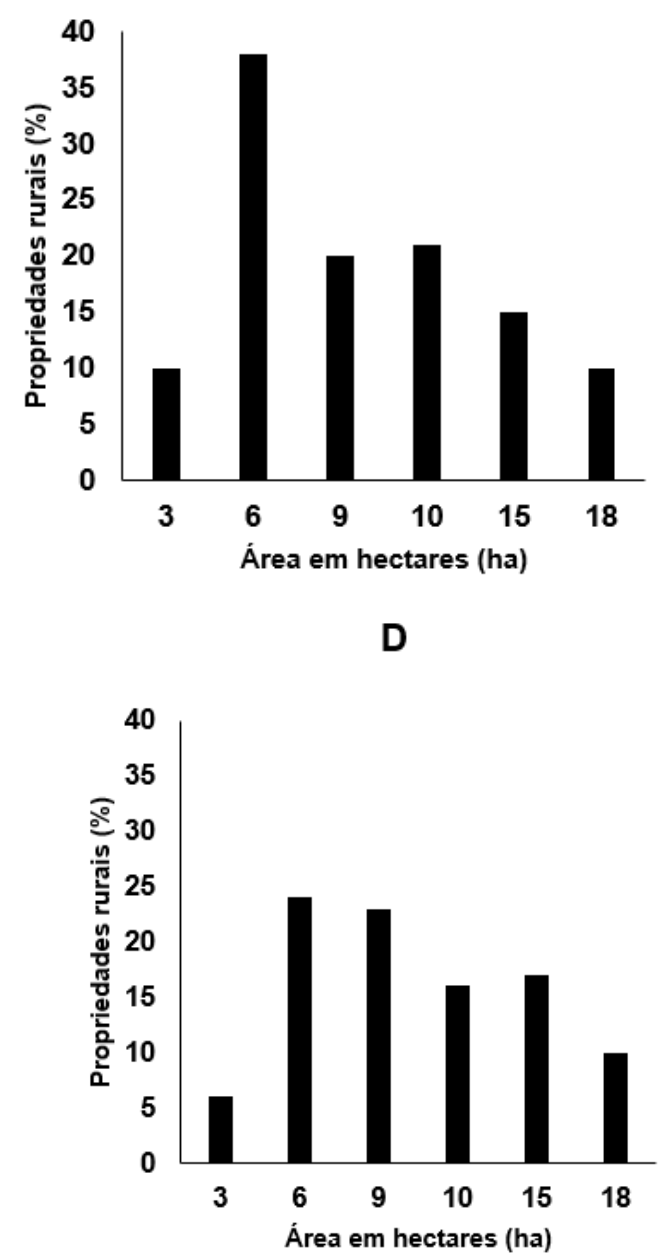

Figura 1. Distribuição das áreas cultivadas com feijão-caupi no município de Calçado (A), Lajedo (B), São João (C) e Caetés localizados no estado de Pernambuco.

Já na Figura 2 encontra-se os resultados referentes aos os problemas apontados pelos agricultores na produção do feijão-caupi. Observa-se que em torno de $15 \%$ dos produtores atribuem como principal dificuldade na cadeia produtiva do feijão a ocorrência de pragas e doenças. Pois, essas além de prejudicarem a produção ainda influenciam na qualidade final do produto. Pois de acordo com Carbonell et al. (2003) um produto saudável terá uma qualidade boa de cozimento que vai chegar ao consumidor final. 


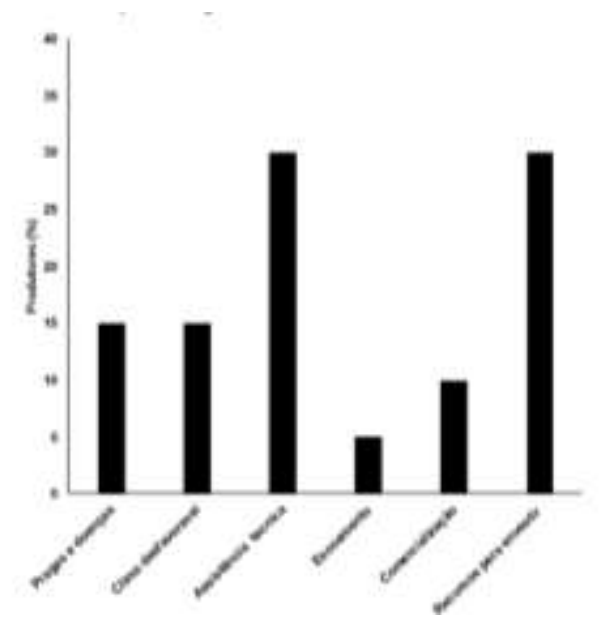

Figura 2: Problemas apontados pelos produtores de feijão caupi.

Aproximadamente $15 \%$ dos produtores também relataram como grande entrave no sistema de produção as condições climáticas desfavoráveis que ocorreram nos últimos anos o que tem contribuído para as baixas produtividades. Sousa et al. (2009) verificaram que o efeito do estresse hídricoem feijoeiro causa reduções nos componentes de produção e émais severo quando ocorre nas fases de floração e frutificação. No mercado já existem cultivares de feijão desenvolvidas tolerantes a seca, mas o baixo poder aquisitivo financeiro dos produtores é um fator limitante para ter acesso.

O problema mais grave enfrentado pelos os produtores é a falta de assistência técnica com relato de $30 \%$ dos produtores, os quais alegam que que precisam de mais apoio e conhecimento para maximizar a produtividade, no entanto não tem recursos financeiro suficiente para contratar um profissional técnico e os programas governamentais não é suficiente para atender a demanda dos produtores rurais. Uma alternativa poderia ser a organização em cooperativas para fornecer o setor e contratar técnico.
Uma pequena minoria elegeu $\mathrm{o}$ escoamento da produção como problema, uma vez que os acessos das estradas e rodovias do Nordeste brasileiro são bons e a existência de cidades próximas umas das outras facilita o acesso. E como o feijão-caupi é um produto voltado para suprir a necessidade do mercado local, não se requer grandes infraestruturas de transporte.

A comercialização foi apontada por 13\% dos produtores como dificuldade, pois as vendas são realizadas para os atravessadores, fazendo com que a maior participação nos lucros não os favoreça. No que se refere ao processo de comercialização, a aquisição de uma infraestrutura de armazenamento serevela como o principal gargalo, pois a ausência desta infraestrutura obriga a venda imediata após a colheita e beneficiamento do feijão, período em que os preços estão nos níveis mais baixos do ano. Existindo uma grande necessidade para que uma unidade de armazenamento e processamento de feijão-caupi seja criada. Além de permitir condições adequadas de armazenamento pode atuar como vetor da organização dos produtores, estabelecendo melhor articulação entre os elos de produção e comercialização.

$\mathrm{Na}$ liderança dos entraves enfrentado pelos produtores de feijão encontram-se os recursos para investir na agricultura, uma vez que a maioria das propriedades são de pequeno porte e o incentivo governamental para investimento na agricultura familiar tem acentuada redução nos últimos anos pelo o governo brasileiro. A falta de recurso para investimento na agricultura compromete toda a cadeia de produção. Pois com recurso o produtor 
pode adquirir sementes melhoradas e comprar insumos que possam maximizar a produção.

\section{CONCLUSÃO}

O cultivo do feijão-caupi é uma das principais fontes de renda para os agricultores familiares no Nordeste brasileiro, porém devido aos problemas enfrentados na cadeia de produção os produtores rurais podem ter dificuldade de produzir em larga escala e se tornar competitivo.

\section{REFERÊNCIAS}

ALMEIDA, A. L. G.; ALCÂNTARA ROSA, M. C. M.; NOBREGA, R. S. A.; LEITE, L. F. C.; SILVA, J. A. L. Produtividade do feijão-caupi cv BR 17 Gurguéia inoculado com bactérias diazotróficas simbióticas no Piauí. Revista Brasileira de Ciências Agrárias, v.5, n.3, p.364-369, 2010.

BOYER, J. S. Water deficits and photosynthesis. In: KOZLOWSKI, T.T. (ed.) Water deficits and plant growth. New York: Academic Press, v.4, p.154-191, 1978.

CARBONELL, S. A. M.; LIMONTA, C.; PEREIRA, V. R. Qualidade tecnológica de grãos de genótipos de feijoeiro cultivados em diferentes ambientes. Bragantia, v. 62, p. 369-379, 2003.

CONAB. Agricultura familiar. Conab 2009.

Disponívelem:www.conab.gov.br/conteudo.php?a=11 25\&t=2, Acessado em: 15/05/2011.

FERREIRA, J.M. \& SILVA, P.S.L. Produtividade de "feijão verde" e outras características de cultivares de caupi. Pesquisa Agropecuária Brasileira, v.1, n.22, p.55-58, 1987.

FREIRE FILHO, F. R. Origem, evolução e domesticação do caupi.In: ARAÚJO, J. P. P. de; WATT, E. E. (Org.). O caupi no Brasil. Brasília, DF: IITA: EMBRAPA, 1988. p. 26-46.

OLIVEIRA, R. L. L.; MOREIRA, A. R.; COSTA, A. V. A.; SOUZA, L. C. S.; LIMA, L. G. S.; SILVA, T. L. Modelos de determinação não destrutiva de área foliar de feijão caupi Vigna unguiculata (L.). Global Science Snd Technology, v. 8, n. 2, p. 17-27, 2015.
ROSOLEM, C. Nutrição e adubação do feijoeiro. Piracicaba: Ed. POTAFOS, 1987. 93p (Boletim Técnico, 8).

SANTOS, C. A. F.; BARROS, G. A. A.; SANTOS, I. C. C. N.; FERRAZ, M. G. S. Comportamento agronômico e qualidade culinária de feijão-caupi no Vale do São Francisco. Horticultura Brasileira,v.26, n. 3, p. 404-408, 2008.

SILVA, P.S.L. \& OLIVEIRA, C.N. Rendimentos de feijão verde e maduro de cultivares de caupi.

Horticultura Brasileira, v.11, n.2, p. 133-135, 1993.

\begin{tabular}{l}
\hline Abraão Cícero da Silva \\
Doutorando, Programa de Pós-Graduação em \\
Ciência do Solo, Universidade Federal Rural de \\
Pernambuco \\
\hline
\end{tabular}

\begin{tabular}{l}
\hline $\begin{array}{l}\text { Pedro Luís Ribeiro de Vasconcelos } \\
\text { Estudante de Agronomia, Departamento }\end{array}$ \\
$\begin{array}{l}\text { Agronomia, } \\
\text { Pernambuco. }\end{array}$ \\
$\begin{array}{l}\text { UniversidadeFederal Rural } \\
\text { de }\end{array}$ \\
\hline
\end{tabular}

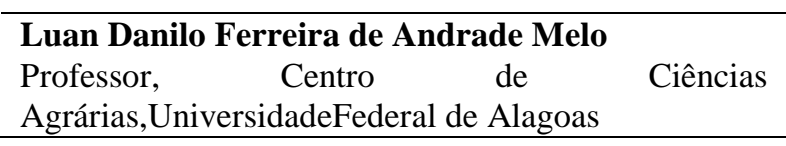

\begin{tabular}{l}
\hline Vinicius Santos Gomes da Silva \\
Pós-doutorando, Programa de Pós-Graduação em \\
Agronomia, Universidade Federal de Alagoas. \\
\hline
\end{tabular}

\begin{tabular}{l}
\hline $\begin{array}{l}\text { João Luciano Melo de Andrade Júnior } \\
\text { Doutorando, Programa de Pós-Graduação em Ciência } \\
\text { do Solo, Universidade Federal Alagoas }\end{array}$ \\
\hline $\begin{array}{l}\text { Mayame de Brito Santana } \\
\text { Doutorando, Programa de Pós-Graduação em } \\
\text { Ciência do Solo, Universidade Federal Rural de } \\
\text { Pernambuco }\end{array}$ \\
\hline
\end{tabular}

